\title{
Case report presenting the diagnostic challenges in a patient with recurrent acquired angioedema, antiphospholipid antibodies and undetectable $\mathrm{C} 2$ levels
}

\author{
Arturo J. Bonnin ${ }^{1 *}$, Charles DeBrosse ${ }^{2}$, Terri Moncrief ${ }^{1}$ and G. Wendell Richmond ${ }^{3}$
}

\begin{abstract}
Background: Angioedema secondary to acquired C1 inhibitor deficiency (AAE) is a rare disease. It usually is associated with lymphoproliferative disorders. We present a case of AAE in a patient with antiphospholipid syndrome (APS), a non-Hodgkin lymphoproliferative disorder ( $\mathrm{NHL}$ ) with undetectable levels of $\mathrm{C2}, \mathrm{C} 4$, and an undetectable $\mathrm{CH} 50$. The co-existence of AAE, APS, and NHL, with an undetectable C2 level, to the best of our knowledge, has never before reported together in the same patient.
\end{abstract}

Case presentation: A patient with a recent history of thrombosis presented with recurrent episodes of angioedema. The workup revealed undetectable levels of $\mathrm{C} 2, \mathrm{C} 4$ and undetectable $\mathrm{CH} 50$. Quantitative levels of $\mathrm{C} 1$ inhibitor and C1q were low. C1 inhibitor function was less than 40\%. Anti-cardiolipin antibodies were found. The patient was initially treated on demand with intravenous plasma-derived human C1-INH concentrates, (Cinryze ${ }^{\circledR}$ Shire). Later the patient received prophylactic therapy with danazol. She was diagnosed with lymphoma 3 years after her first episode of angioedema. Single agent therapy with rituximab was not only effective in treating her lymphoma but also preventing further episodes of angioedema. Anti-cardiolipin antibody titers also declined. Additionally, marked early primary pathway complement component abnormalities and $\mathrm{CH} 50$ also corrected, although incomplete normalization of $\mathrm{C} 4$ proved to be due to a heterozygous C4 deficiency.

Conclusion: This case shows the unique association of AAE, APS and NHL in a patient with undetectable levels of early complement components. Additionally, this case also shows for the first time the effectiveness of rituximab therapy in all three disease states while co-existing simultaneously in the same patient.

Keywords: Acquired angioedema, Antiphospholipid antibody syndrome, C1 inhibitor deficiency, C2 deficiency, Lymphoma, Rituximab, Heterozygous C4 deficiency

\section{Background}

Angioedema secondary to acquired $\mathrm{C} 1$ inhibitor deficiency (AAE) presents with recurrent episodes of skin and mucosal swelling clinically indistinguishable from the hereditary form. Clinically the two are differentiated by the later onset of symptoms in AAE and the lack of

\footnotetext{
*Correspondence: ajbonnin@gmail.com

${ }^{1}$ Department of Internal Medicine, Wright State University Boonshoft School of Medicine, Allergy and Asthma Centre of Dayton, 8039 Washington Village Drive, Suite \#100, Centerville, Dayton, OH 45458, USA Full list of author information is available at the end of the article
}

family history of angioedema [1]. The prevalence of AAE has been estimated to be around 1: 600,000 [2]. The association of AAE with APS has been reported rarely [3-6], though its association preceding or following MGUS (monoclonal gammopathy of undetermined significance) and lymphomas is a common one [7]. Low serum C2 and $\mathrm{C} 4$ levels have been frequently found in AAE since the disease was first reported in the literature [8]. A low CH50 may be detected in any disease that involves activation of the classical complement pathway, but an 
undetectable $\mathrm{CH} 50$ suggests that a complement component is markedly depleted, functionally deficient or absent [9].

We report a case of AAE in a patient with APS with undetectable levels of complement $\mathrm{C} 2, \mathrm{C} 4$, and an undetectable $\mathrm{CH} 50$ who initially was found in a 24-h urine collection for immunofixation to have a free monoclonal kappa light chain. She was first diagnosed with monoclonal gammopathy of undetermined significance (MGUS), and eventually with NHL 3 years after her first episode of angioedema. We present in this report the serial evolution of those complement parameters with danazol and rituximab therapies and afterwards when she was in clinical remission. To our knowledge our patient is the first case reported to demonstrate the combination of these three diseases, with absence of not only $\mathrm{C} 4$, but also $\mathrm{C} 2$, coexisting in the same patient and all three conditions to be responsive to rituximab therapy.

\section{Case presentation}

A $64 \mathrm{y} / \mathrm{o}$ Caucasian female developed pain in her left leg in December 2008. A venous ultrasound identified a thrombus. Her use of supplemental estrogen was felt to be a contributing factor. She was placed initially on enoxaparin followed by warfarin for 6 months. Thereafter she received aspirin $81 \mathrm{mg}$ daily.

In January 2009, she developed mild facial and lip swelling initially attributed to facial trauma from a cat scratch. She went to the emergency department (ED) where she was treated with antihistamines and steroids and released. However, later that night she experienced oropharyngeal swelling and she returned to the emergency department. She was admitted to the intensive care unit for observation and treatment with antihistamines and systemic steroids. Evaluation by otorhinolaryngology during her admission revealed oropharyngeal edema, however, the remainder of her evaluation was unremarkable. She was discharged home 3 days later.

During the admission, an undetectable $\mathrm{C} 4$ level was identified. She was then referred to allergy/immunology for evaluation of angioedema and an undetectable C4 level. The family history for angioedema was negative. A review of her medication list to identify medications classically associated with an increased risk of angioedema revealed that she was taking aspirin $81 \mathrm{mg}$ once daily but had not been on an angiotensin converting enzyme inhibitor. She was no longer on estrogen therapy. She had no history of diseases associated with C4 deficiency including Systemic Lupus Erythematous (SLE) and macular degeneration.

Further laboratory workup after the undetectable $\mathrm{C} 4$ level had been confirmed, revealed low quantitative levels of $\mathrm{C} 1$ inhibitor and C1q. C1 inhibitor function was less than $40 \%$. The clinical and laboratory data suggested a diagnosis of AAE. Further complement studies revealed an undetectable level of C2 (Table 1). A C1q binding assay was positive although a C3d binding immune complex assay was negative. An initial C1q level was below the level of detection but a hemolytic $\mathrm{Clq}$ functional assay was normal, suggesting C1q consumption. $\mathrm{C} 2$ level and function were low, $\mathrm{C} 3$ level and function were nor$\mathrm{mal}$, and $\mathrm{C} 4$ level was undetectable and function was zero (Table 2). Free and bound IgG anti-C1 esterase inhibitor measured by enzyme-linked immunosorbent assay (ELISA) was negative. An assay for IgG anti-C1q antibody was negative. Assays for IgA or IgM anti-C1 inhibitor or anti-C1q antibodies were not available (Table 3). An ANA, anti-SSA/SSB and dsDNA antibodies were negative. IgG, IgM and IgA anti-cardiolipin antibodies were positive. The titer for IgM anti-phosphatidyl serine antibody was 163.1 (normal<22 MPS), and an IgA anti-beta 2 glycoprotein antibody level was 103.8 (normal <20 AU). No lupus anticoagulant was detected. APS was diagnosed on March 2009.

Serum protein electrophoresis (SPE) with immunofixation was negative. Urine electrophoresis with immunofixation was positive for free monoclonal kappa light chains. Chest, abdominal and pelvic CT scans did not show adenopathy or organomegaly. She was referred to hematology/oncology. A bone marrow biopsy was normal on pathological analysis and flow cytometry. A positron emission tomography (PET) scan was negative. All these findings led to a diagnosis of MGUS.

The patient had five more episodes of facial and oropharyngeal edema through July 2011, each requiring hospital admission. Acute treatment with 1000 units purified pdf-C1INH (Cinryze, Shire) was effective at curtailing episodes although on two occasions, a second dose was needed (Fig. 1). Patient weighted around $81 \mathrm{~kg}$ during the times she received purified pdf-C1INH. After the fifth hospitalization the potential risks and benefits of prophylactic treatment were discussed with the patient. Because of her APS and recent history of DVT, it was mutually decided to initiate danazol therapy. Doses of $100 \mathrm{mg}$ twice daily prevented further episodes. The dose was then decreased to the lowest effective dose of $100 \mathrm{mg}$ in the morning and $50 \mathrm{mg}$ at bedtime. On demand icatibant was prescribed in August 2011 when it received FDA approval but was not been administered due to success of other therapeutic interventions. Danazol was continued until March 2013.

In January 2012, she began to experience night sweats and fatigue. Her physical examination revealed the presence of splenomegaly. Her $\mathrm{CBC}$ revealed anemia, leukopenia, and thrombocytopenia. Her LDH and beta-2-microglobulin were elevated. Serum protein 
Table 1 Baseline biological parameters of the patient and its changes with treatment

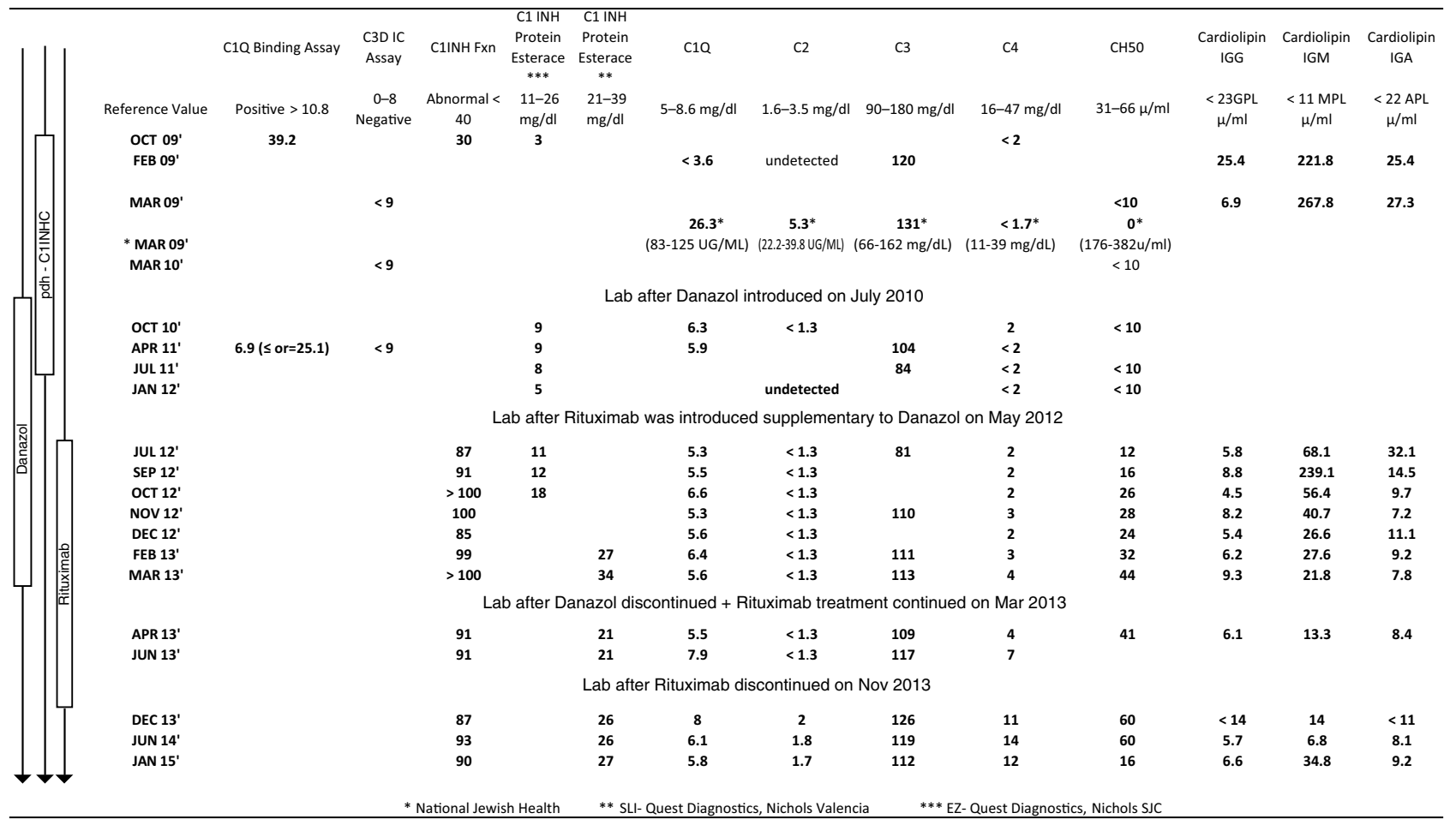

Table 2 Complement Function and Level of the Patient on March 2009

\begin{tabular}{lllll}
\hline & Complement function & Reference range (units/mL) & Complement level & Reference range \\
\hline C1Q & 2949 & $2515-9414$ & 26.3 & $83-125 \mathrm{UG} / \mathrm{mL}$ \\
C2 & 104 & $15,354-46,242$ & 5.3 & $22.2-39.8 \mathrm{UG} / \mathrm{mL}$ \\
C3 & 16,725 & $11,249-42,887$ & 131 & $66-162 \mathrm{mg} / \mathrm{dL}$ \\
C4 & 0 & $400,000-43,000,000$ & $<1.7$ & $11-39 \mathrm{mg} / \mathrm{dL}$ \\
CH50 & 0 & $176-382$ & & \\
\hline
\end{tabular}

Labs performed at National Jewish Health, Denver, Colorado

Table 3 Complement and C1 EST IHN autoantibody profile

\begin{tabular}{lll}
\hline Antibodies & Result & Reference range \\
\hline C1 Q autoantibody & 3 & {$[<4.2] \%$ of STD } \\
C1 EST IHN_autoantibody free lgG & 25.4 & {$[0.89-39.1] \%$ of STD } \\
C1 EST IHN_-autoantibody bound lgG & 3 & {$[0.3-46.3] \%$ of STD } \\
\hline
\end{tabular}

Labs performed at National Jewish Health, Denver, Colorado

electrophoresis revealed an elevation of alpha 2 globulin fraction, with an $\mathrm{M}$ - band present in the gamma region. Immunofixation revealed a monoclonal IgM-Kappa gammopathy. A bone marrow biopsy was performed for the second time. It showed infiltration by monoclonal lymphocytes. Immunoperoxidase stains identified
CD5-CD10+ CD20+ and BCL6+ cells, consistent with follicular lymphoma. A PET scan was done and revealed strong spleen uptake. The patient was diagnosed with low-grade B cell non-Hodgkin's lymphoma, stage IV-B in April 2012. Treatment options were discussed with the patient. It was elected to treat her with a single agent, rituximab. Treatment was initiated in May 2012 with four doses of rituximab at $375 \mathrm{mg} / \mathrm{m}^{2}$, as initial induction therapy. By the end of the induction phase she was not experiencing night sweats or fatigue and her anemia, leukopenia and thrombocytopenia had resolved. A post treatment PET scan was negative. The patient declined another bone marrow biopsy. Following successful induction therapy, a maintenance schedule with rituximab at $375 \mathrm{mg} / \mathrm{m}^{2}$ was given. 

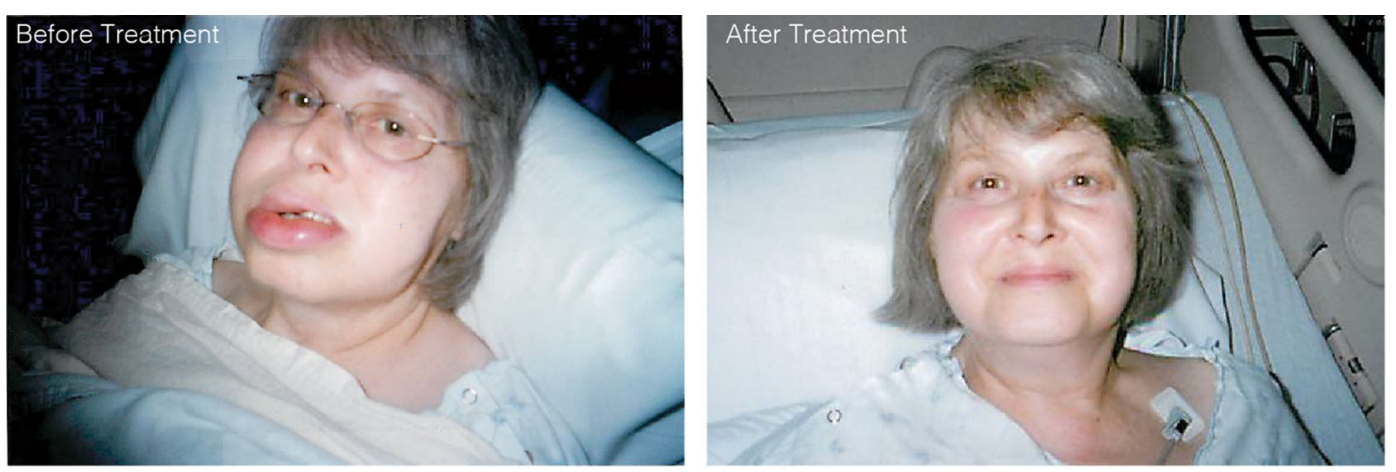

Fig. 1 Swelling of patient before and after $24 \mathrm{~h}$ of treatment

Immunologic re-evaluation after initiation of rituximab therapy, found that her anti-cardiolipin antibodies levels decreased. The $\mathrm{C} 4$ quantitation remained below normal levels, although the $\mathrm{C} 1$ inhibitor functional assay normalized. Because of persistently decreased $\mathrm{C} 4$ levels, C4-genetic analysis was done. The $\mathrm{C} 4$ protein concentration by radio immunodiffusion assay was $13.4 \mathrm{mg} / \mathrm{dL}$. Immunofixation of EDTA plasma detected C4A3 and C4B1 protein allotypes. Quantitative real-time polymerase reactions for complement $\mathrm{C} 4$ gene copy numbers performed in three independent experiments revealed: Total $\mathrm{C} 4=3, \mathrm{C} 4 \mathrm{~A}=1, \mathrm{C} 4 \mathrm{~B}=2$. These results are compatible with heterozygous $\mathrm{C} 4 \mathrm{~A}$ deficiency, suggesting a genetic component for the low levels of $\mathrm{C} 4$ observed in this patient. A follow-up interview with the patient in July 2016 found that she remained lymphoma free and without recurrence of angioedema or any thrombotic events.

\section{Discussion and conclusions}

AAE association with lymphoproliferative disorders or autoantibodies is well established [10, 11]. AAE is uncommon. However, recently series have reported the presentation, associations and responses to treatment in large cohorts of patients with $\operatorname{AAE}[2,7,12]$. This patient, in addition to having AAE, met the Sapporo Criteria for the diagnosis of Antiphospholipid Syndrome [13]. APS has rarely been reported to be associated with acquired $\mathrm{C} 1$ inhibitor deficiency [3-6].

The presentation of angioedema at 64 years of age in the presence of a low $\mathrm{C} 4$, suggested she had AAE. The detection of a quantitatively decreased $\mathrm{C} 1$ inhibitor in combination with decreased $\mathrm{C} 1$ inhibitor function was diagnostic of a $\mathrm{C} 1$ inhibitor deficiency. A combination of low $\mathrm{C} 4$ and low $\mathrm{C} 1$ inhibitor function has $98 \%$ specificity for $\mathrm{C} 1$ inhibitor deficiency and a $96 \%$ negative predictive value [14]. With the discovery that the patient had a normal SPE and a normal serum immunofixation, we entertained the possibility that the pathogenesis of her angioedema was due to an autoimmune process like her APS. The undetectable levels of $\mathrm{C} 2, \mathrm{C} 4$ and an undetectable $\mathrm{CH} 50$ suggested either a primary $\mathrm{C} 2$ or $\mathrm{C} 4$ deficiency, or less likely, a secondary deficiency due to autoantibody production and marked complement consumption [9]. Additional data revealing a low $\mathrm{C} 1 \mathrm{q}$ level and positive $\mathrm{C} 1 \mathrm{q}$ binding activity suggested an acquired $\mathrm{C} 1$ inhibitor deficiency due to anti-C1 inhibitor autoantibodies. Using an IgG- specific detection assay, anti-C1 inhibitor was not detected. The failure to detect an IgG anti-C1 inhibitor is not surprising since $30 \%$ of patients with acquired $\mathrm{C} 1$ inhibitor deficiency have undetectable anti-C1 inhibitor antibodies [15]. A limitation of our case presentation is that we were not able to check for IgA or IgM anti-C1 inhibitor antibodies, which can be present in AAE [7].

In an ongoing effort to evaluate for a lymphoproliferative process, a 24-h urine collection for immunoelectrophoresis and immunofixation was done. It was positive for a free kappa light chain. Further workup for a lymphoproliferative disorder was negative. Interestingly, serum immunofixation was repeated 3 years later and was found to be positive for a monoclonal IgM kappa component, suggesting that the acquired $\mathrm{C} 1$ inhibitor deficiency in this patient was related to a lymphoproliferative process and its $\mathrm{M}$ component. Previous studies have shown that the $\mathrm{M}$ component may have anti-C1-INH autoantibody neutralizing activity [15].

Her NHL immunophenotype was consistent with follicular lymphoma. The most common lymphoma associated with cases of $\mathrm{AAE}$, is splenic marginal zone lymphoma [7, 12]. However, the most frequent type of lymphomas associated with $\mathrm{C} 1$ inhibitor deficiency, symptomatic or not, in a case series of patients with lymphoma was diffuse large B cell lymphoma [16].

Once the diagnosis of AAE was established, human pdC1INHc (Cinryze-Shire) was made available for immediate administration upon this patient's presentation 
in the ED. Although a dose of 1000 units was generally effective at stopping the progression of her angioedema, a second dose with 1000 units was administered within $24 \mathrm{~h}$ on her fourth and sixth admissions due to the persistence of lower lip swelling. Due to the recurrent nature of her angioedema episodes, we elected to try danazol. Tranexamic acid is considered to be more effective than danazol $[2,7]$. Despite studies showing patients receiving danazol for $>2$ years had increased coagulation [17], the known increased risk of thrombosis in patients receiving antifibrinolytics [2], influenced the decision to start the danazol trial. Danazol has been used extensively in both hereditary angioedema and AAE $[18,19]$ due to its ability to efficiently increase $\mathrm{C} 1$ inhibitor production. In our patient, danazol was well tolerated and it did prevent further episodes of AAE as long as the total dose was not lower than $150 \mathrm{mg} /$ day. In addition to observe clinical benefits, the complement profile did change, similar to previous reports [19]. Later rituximab, a B cell depleting chimeric anti-CD20 monoclonal antibody [20], was used as monotherapy to treat her NHL. Although initially used in the treatment of lymphomas, it has also been used in a multitude of autoimmune diseases. Its use in APS has seldom been reported [21]. Furthermore, its administration has been reported only in individual cases of AAE patients [7, 22-25]. Its efficacy on the three coexisting conditions of our patient probably depends in that all her diseases were consequence of a monoclonal IgM kappa producing $\mathrm{B}$ cell lymphoproliferation.

A quantitatively undetectable $\mathrm{C} 2$ and essentially absent $\mathrm{C} 2$ function posed an interesting interpretative problem. While it is known that $\mathrm{C} 2$ levels are decreased in patients with $\mathrm{C} 1$ inhibitor deficiency [26], the finding of an undetectable $\mathrm{C} 2$ is not. This data strongly suggested a potential C2 deficiency, although she did not have history of recurrent pyogenic infections, SLE, or atherosclerosis commonly associated with homozygous $\mathrm{C} 2$ deficiency [27]. Normalization of $\mathrm{C} 2$ levels after treatment with rituximab ruled out a $\mathrm{C} 2$ deficiency and suggested a consumptive process for its markedly low level. Interestingly her $\mathrm{C} 4$, also undetectable initially, never normalized, suggesting a heterozygous $\mathrm{C} 4$ deficiency. This was confirmed by $\mathrm{C} 4$ genotyping studies showing that the patient had a single C4A gene and two C4B genes. Complement deficiencies have been associated with SLE and other autoimmune disorders, but are rarely reported to be associated to APS [28].

In conclusion, this patient presented with a complicated clinical course culminating in the detection of a monoclonal IgM producing lymphoproliferative disease. The pathological B cell proliferation likely was ultimately responsible for her $\mathrm{C} 1 \mathrm{INH}$ deficiency and APS. The complement abnormalities detected are likely multifactorial. Studies of patients with antiphospholipid antibodies have shown that these patients uniformly have significantly elevated complement activation products [29]. This, in combination with complement activation due to the intrinsic complement binding capacity of the monoclonal IgM protein or its potential role as an autoantibody, as evidenced by the acquired $\mathrm{C} 1$ inhibitor deficiency, lead to the uncontrolled, marked consumption of early complement components. The heterozygous C4 deficiency resulted in the expected decrease in C4 level that increased but never normalized after rituximab therapy. Prior to therapy, baseline, 'normally' decreased C4 levels were rapidly consumed by a monoclonal IgM kappa-associated lymphoproliferative disease causing $\mathrm{C} 1$ inhibitor depletion and ongoing complement consumption resulting in undetectable levels.

This case is unique for multiple reasons. To the best of our knowledge this is the first reported case of an undetectable $\mathrm{C} 2$ in a patient presenting with AAE. Also, this is the first report of AAE, APS and NHL co-existing in the same patient. Furthermore, simultaneous serological improvement induced by rituximab monotherapy in all three diseases has not being previously reported. Clinically her AAE and NHL improved with administration of rituximab, but it is not clear if there was clinical benefit in the patient's APS from rituximab as previously reported [21]. She did not show any evidence of thrombotic recurrence from 2009 to 2012 in spite of no anticoagulant therapy. Interestingly, there was clinical improvement in the frequency of angioedema episodes with the administration of an attenuated androgen, danazol. This improvement was associated with a partial correction of some of the complement abnormalities, most notably an increase in $\mathrm{C} 1 \mathrm{INH}$ level, although never attaining a normal' level. Near complete resolution of serological and clinical findings required the correction of the monoclonal proliferative process by rituximab. This lymphoproliferative process, either alone, or concomitantly with anti-cardiolipin antibodies, drove marked complement consumption resulting in the markedly abnormal complement findings described herein.

\section{Abbreviations \\ AAE: angioedema secondary to acquired C1 inhibitor deficiency; APS: antiphospholipid syndrome; ED: emergency department; SLE: systemic lupus erythematous; PET: positron emission tomography; MGUS: monoclonal gam- mopathy of undetermined significance; SPE: serum protein electrophoresis; pdh-C1INH: plasma-derived human C1-INH concentrates; NHL: non-Hodgkin lymphoproliferative disorder.}

\section{Authors' contributions}

$A B$ has done all the analysis of the data, writing the paper, organization of the tables, and distributing the work to be done by the co-authors. He also has found and read the majority of references used in this paper. CD and TM has participating giving their suggestions and editing the paper from the beginning to the end. WR helped editing the paper from the beginning to the 
end, helped finding and analyzing some references, analyzing data, and his thoughts were essential for this paper. All authors read and approved the final manuscript.

\section{Author details \\ ${ }^{1}$ Department of Internal Medicine, Wright State University Boonshoft School of Medicine, Allergy and Asthma Centre of Dayton, 8039 Washington Village Drive, Suite \#100, Centerville, Dayton, OH 45458, USA. ${ }^{2}$ Allergy and Asthma Centre of Dayton, Dayton, OH, USA. ${ }^{3}$ Western Springs Asthma and Allergy, Western Spring, IL, USA.}

\section{Author's information}

Dr. Bonnin is an associate professor of internal medicine at WSU. He teaches medical students and family and internal medicine residents. He has published a case report in complement deficiency (Factor I), and also on hereditary angioedema type II. Dr. DeBrosse published while in training in eosinophilic esophagitis and Dr. Moncrief in epidemiology. Dr. Richmond was in academic medicine for about 20 years. Director of the Allergy and Immunology division at Rush Medical Center. He has published in immunodeficiency.

\section{Acknowledgements}

None

\section{Competing interests}

The authors declare that they have no competing interests.

\section{Availability of data and materials}

I keep all the data presented in this paper at the office where the patient was seen as outpatient. The majority of the data is kept in paper form, as the practice was not using electronic records on those dates. The majority of the information has been since scanned into her electronic medical record as well as more recent communications with the patient.

\section{Consent for publication}

We have on hand the permission in writing by the patient to publish her case in a medical journal. She also gave us the permission to use her photograph for publication.

\section{Ethics approval and consent to participate}

This publication is based on a clinical case of a patient treated with FDA approved medications, therefore none to declare.

\section{Funding}

None of the authors has received any funding for this publication.

\section{Publisher's Note}

Springer Nature remains neutral with regard to jurisdictional claims in published maps and institutional affiliations.

Received: 1 September 2017 Accepted: 30 March 2018 Published online: 04 June 2018

\section{References}

1. Cicardi M, Zanichelli A. Acquired angioedema. Allergy asthma. Clin Immunol. 2010;6:14-8.

2. Zanichelli A, Azin GM, Wu MA, Suffritti C, Maggioni L, Caccia S, Parego F, Vacchini R, Cicardi M. Diagnosis, course and management of angioedema in patients with acquired C1-inhibitor deficiency. J Allergy Clin Immunol Pract. 2017;5:1307-13.

3. Nagy L, Hannema A, Swaak A. Acquire C1 inhibitor deficiency associated with systemic lupus erythematous, secondary antiphospholipid syndrome and IgM monoclonal paraproteinemia. Clin Rheumatol. 1999;18:56-8.

4. Barilla-Labarca M-L, Gioffre D, Zanichelli A, Cicardi M, Atkinson JP. Acquired C1 esterase inhibitor deficiency in two patients with lupus-like syndrome and anticardiolipin antibodies. Arthritis Rheum. 2002;47:223-6.
5. Szeplaki G, Varga L, Szepvolgyi A, Simon K, Blasko B, Nagy E. Karadi, Fust G, Farkas $\mathrm{H}$ : acquire angioedema associated with primary antiphospholipid syndrome in a patient with antithrombin III deficiency. Int Arch Allergy Immunol. 2008;146:164-8.

6. Di Leo E, Netis E, Montinaro V, Calogiuri G, Denelle Donne P, Ferrannini A, Vacca A. Acquired angioedema with C 1 inhibitor deficiency associated with anticardiolipin antibodies. Int J Immunopathol Pharmacol. 2011;24:1115-8.

7. Gobert D, Paule R, Ponard D, Levy P, Fremeaux-Bacchi V, Bouillet L, Boccon-Gibod I, Drouet C, Gayet S, Launay D, Martin L, Mekinian A, Leblond V, Fain O. A nationwide study of acquire C-1 inhibitor deficiency in France, characteristics and treatment responses in 92 patients. Medicine. 2016;95:33.

8. Caldwell JR, Ruddy S, Schur PH, Austen KF. Acquire C1 deficiency in Iymphosarcoma. Clin Immunol Immunopathol. 1972;1:39-52.

9. Wen L, Atkinson JP, Giclas PC. Clinical and laboratory evaluation of complement deficiency. J Allergy Clin Immunol. 2004;113:585-93.

10. Schreiber AD, Zweiman B, Atkins P, Goldwein F, Pietra G, Atkinson B, Abdou NI. Acquired angioedema with lymphoproliferative disorder: association of C1 inhibitor with cellular abnormality. Blood. 1976;48:567-80.

11. Jackson J, Sim RB, Whelan A, Feighery C. An IgG autoantibody which inactivates C1- inhibitor. Nature. 1986:323:722-4.

12. Castelli R, Wu M, Arquati M, Zanichelli A, Suffritti C, Rossi D, Cicardi M. High prevalence of splenic marginal zone lymphoma among patients with acquire C1 inhibitor deficiency. Br J Hematol. 2016;172:902-8.

13. Miyakis S, Lockshin MD, Atsumi T, Branch DW, Brey RL, Cervera R, Derksen RHWM, De Groot PG, Koike T, Meroni PL, Reber G, Shoenfeld Y, Tincani A, Vlachoyiannopoulos PG, Krilis SA. International consensus statement on an update of the classification criteria for definite antiphospholipid syndrome (APS). J Thromb Haemost. 2006;4:295-306.

14. Gompels MM, Lock RJ, Morgan JE, Osborne J, Brown A, Virgo PF. A multicentre evaluation of the diagnostic efficiency of serological investigations for C1 inhibitor deficiency. J Clin Pathol. 2002;55:145-7.

15. Cicardi M, Beretta A, Colombo M, Gioffre D, Cugno M, Agostini A. Relevance of lymphoproliferative disorders and of anti-C1 inhibitor autoantibodies in acquired angio-oedema. Clin Exp Immunol. 1996;106:475-80.

16. Bekos C, Perkmann T, Krauth M, Raderer M, Lechner K, Jaeger U. Acquire C1 esterase inhibitor deficiency in lymphomas: prevalence, symptoms, and response to treatment. Leuk Lymphoma. 2016;57:2033-6.

17. Birjmohun RS, Hovingh KS, Stroes ES, Hoftra JJ, Dallinga-Thie GM, Meijers JC, Kastelein JJ, Levi M. Effects of short term and long term danazol treatment on lipoproteins, coagulation, and progression of atherosclerosis: two clinical trials in healthy volunteers and patients with hereditary angioedema. Clin Ther. 2008;30:2314-23.

18. Hauptmann G, Mayer S, Lang JM, Oberling F, Mayer G. Treatment of acquire C1 - inhibitor deficiency with danazol. Ann Intern Med. 1977:87:577-8

19. Higa S, Hirata H, Ninami S, Hashimoto S, Suemura M, Saeki Y, Kawase I, Tanaka T. Autoimmune acquired form of angioedema that responded to danazol therapy. Intern Med. 2002;41:398-402.

20. Maloney DG. Anti-CD20 antibody therapy for B-cell lymphomas. N Engl J Med. 2012;366:2008-16.

21. Pons I, Espinosa G, Cervera R. Efficacy and safety of rituximab in the treatment of primary antiphospholipid syndrome: analysis of 24 cases from a bibliography review. Med Clin (Barc). 2015;144:97-105.

22. Branellec A, Bouillet L, Javaud N, Mekinian A, Boccon-Gibod I, BlanchardDelaunay C, Oksenhendler E, Ollivier Y, Dunogué B, Amarger S, Ponard D, Drouet C, Mouthon L, Thomas M, Fain O. French national reference center for angioedema (CREAK). Acquired C1-inhibitor deficiency: 7 patients treated with rituximab. J Clin Immunol. 2012;32:936-41.

23. Dreyfus DH, Na CR, Randolph CC, Kearney D, Price C, Podell D. SuCcessful rituximab B lymphocyte depletion therapy for angioedema due to acquired C1 inhibitor protein deficiency: association with reduced C1 inhibitor protein autoantibody titers. Isr Med Assoc J. 2014;16:315-6.

24. Doshi A, Tse K, Riedl M, Zuraw B, Christiansen S. Cases of acquired C1 inhibitor deficiency treated with rituximab. J Allergy Clin Immunol Pract. 2016:4:987-8. 
25. Bygum A, Vestergaard $\mathrm{H}$. Acquired angioedema-occurrence, clinical features and associated disorders in a danish nationwide patient cohort. Int Arch Allergy Immunol. 2013;162:149-55.

26. Kaplan AP, Joseph K. Complement, kinins, and hereditary angioedema: mechanisms of plasma instability when C1 inhibitor is absent. Clin Rev Allergy Immunol. 2016;51:207-15.

27. Truedsson L. Classical pathways deficiencies-A short analytical review. Mol Immunol. 2015;68:14-9.
28. Yang JW, Rich E, Saint-Cyr C, Bourre-Tessier J. Combined hereditary heterozygous $\mathrm{C} 2$ and $\mathrm{C} 4$ deficiencies: variable clinical and serological manifestations among three sisters. Curr Rheumatol Rev. 2016;12:1-3.

29. Breen KA, Seed P, Parmar K, Moore GW, Stuart-Smith SE, Hunt BJ. Complement activation in patients with isolated antiphospholipid antibodies or primary antiphospholipid syndrome. Thromb Haemost. 2012;107:423-9.
Ready to submit your research? Choose BMC and benefit from:

- fast, convenient online submission

- thorough peer review by experienced researchers in your field

- rapid publication on acceptance

- support for research data, including large and complex data types

- gold Open Access which fosters wider collaboration and increased citations

- maximum visibility for your research: over $100 \mathrm{M}$ website views per year

At BMC, research is always in progress.

Learn more biomedcentral.com/submissions 